BBA $55 \mathrm{I} 57$

\title{
METABOLISM OF PHOSPHOLIPIDS BY POLYMORPHONUCLEAR LEUKOCYTES
}

\author{
P. ELSBACH, J. W. O. VAN DEN BERG, H. VAN DEN BOSCH AND
}

L. L. M. VAN DEENEN

Department of Medicine of New York University School of Medicine, New York, N.Y., and The Department of Biochemistry, Laboratory of Organic Chemistry, The State University of Utrecht, Utrecht (The Netherlands)

(Received January IIth, 1965)

SUMMARY

By incubating homogenates of polymorphonuclear leukocytes obtained from rabbit-peritoneal exudates with various ${ }^{32} \mathrm{P}$-labeled phosphoglycerides the following reactions were identified:

Lecithin $\rightarrow$ Lysolecithin and fatty acid

Lysolecithin $\rightarrow$ Glycerylphosphorylcholine and fatty acid

Lysolecithin $\rightarrow$ Lecithin

The mechanism of the last reaction appears to be the recently postulated (ERBLAND and MarinetTi) pathway:

2 lysolecithin $\rightarrow$ lecithin and glycerylphosphorylcholine. This conclusion is based upon: (a) $\left[{ }^{32} \mathrm{P}\right]$ lysolecithin accumulation occurred without appreciable incorporation of $\left[{ }^{14} \mathrm{C}\right]$ linoleic acid. (b) Lysolecithin carrying ${ }^{32} \mathrm{P}$ in the phosphorylcholine moiety and ${ }^{14} \mathrm{C}$ in the fatty acid yielded lecithin with a ${ }^{14} \mathrm{C} /{ }^{32} \mathrm{P}$ ratio 2 times that of the original lysolecithin. (c) ATP and $\mathrm{CoA}$ did not stimulate $\left.{ }^{32} \mathrm{P}\right]$ lecithin formation nor incorporation of $\left[{ }^{14} \mathrm{C}\right]$ linolcic acid.

Lysolecithin is a membrane-lytic agent. Its production and removal by conversion to glycerylphosphorylcholine and lecithin may therefore play a role in the lysis and renewal of cellular membranes.

\section{INTRODUCTION}

Isotopic labeling of phospholipids of polymorphonuclear leukocytes obtained from peritoneal exudates produced in rabbits and guinea-pigs has been demonstrated using $\left[\mathrm{I}^{-14} \mathrm{C}\right]$ acetate $^{1,2},{ }^{32} \mathrm{P}$ (see ref. 2 ) and $\mathrm{I}^{-14} \mathrm{C}$ - labeled long-chain fatty acids ${ }^{3-5}$.

In addition to synthetic pathways, polymorphonuclear leukocytes contain several phospholipid-splitting enzymes ${ }^{6}$.

This report presents a further exploration of several aspects of phospholipid metabolism by homogenates of rabbit polymorphonuclear leukocytes. In the present study the conversion of lysolecithin to lecithin according to a recently postulated? and subsequently confirmed ${ }^{8,9}$ pathway has been shown to occur in these mammalian cells. 
Furthermore the nature of the phospholipid-splitting activities in leukocyte homogenates has been more closely identified.

\section{MATERIALS AND METHODS}

Cells

Leukocytes were obtained from peritoneal exudates elicited in rabbits as described before ${ }^{10}$. Homogenates of the cells were prepared in $0.25 \mathrm{M}$ sucrose, using a glass homogenizing tube and a motor-driven teflon pestle ${ }^{6}$. In a few experiments, fractionation of whole homogenates was carried out according to the technique of CoHN AND HIRsch ${ }^{11}$ in $0.34 \mathrm{M}$ sucrose. This method of fractionation of leukocytes yields three fractions: (a) a $400 \times g$ crude sediment consisting of large membrane fragments, nuclei and an occasional unbroken cell, (b) a supernatant fraction obtained by centrifugation at $8200 \times g$ of the homogenate remaining after spinning at $400 \times g$, and an $8200 \times g$ sediment consisting mainly of the typical leukocyte granules ${ }^{11}$.

\section{Radioactive substances}

Isotopically labeled phospholipids were prepared biosynthetically by incubation of rat-liver slices with ${ }^{32} \mathrm{P}\left(\mathrm{K}_{2} \mathrm{H}^{32} \mathrm{PO}_{4}\right.$, Amersham, Radiochemical Centre, (Great Britain)). Lipid extracts of the incubated liver tissue ${ }^{12}$ were fractionated on silica gelstarch thin-layer plates ${ }^{\ominus}$. The lipid material was applied in a narrow band across the plate and separation into various phospholipid fractions was achieved in a solvent system consisting of chloroform-methanol-water $(65: 35: 4, v / v)$. The radioactive fractions were located by radioantography using Agfa X-ray paper (Agfa A.G., Leverkusen (Germany)), scraped off the plate and the labeled material eluted from the silica gel with methanol employing small glass columns. The eluted fractions were then tested for purity by paper-chromatography according to MARINETTI ${ }^{13}$, their location determined by counting in a strip-counter and their identity established against reference compounds following staining with Rhodamine $6 \mathrm{G}$ spray ${ }^{13}$. In this manner $\left[{ }^{32} \mathrm{P}\right]-$ phosphatidylethanolamine and phosphatidylcholine were obtained in good yield. The labeled lyso-compound was prepared by incubation of [ $\left.{ }^{32} \mathrm{P}\right]$ phosphatidylcholine in $\mathrm{I} \mathrm{ml}$ of $0.02 \mathrm{M} \mathrm{CaCl}_{2}$ containing I $\mathrm{mg}$ of Crotalus adamanteus venom (Lights and Co., Colnbrook, Bucks. (Great Britain)). This enzyme preparation attacks only the 2 -fatty ester linkage of the phosphoglyceride molecule ${ }^{14}$. Dispersion of the $\left[{ }^{32} \mathrm{P}\right]$ lecithin was achieved by ultrasonication. Breakdown of the $\left[{ }^{32} \mathrm{P}\right]$ lecithin was usually virtually complete in $2-4 \mathrm{~h}$ of rapid agitation at room temperature. The incubation mixture was extracted in chloroform-methanol $(\mathrm{I}: \mathrm{I}, \mathrm{V} / \mathrm{V})$ and the extract filtered and evaporated. The lipid residue in a small amount of methanol was then placed on a thin-layer silica gel-starch plate and the $\left.{ }^{32} \mathrm{P}\right]$ lysolecithin obtained as indicated above.

Conversion of $\left[{ }^{32} \mathrm{P}\right]$ lysolecithin to glyceryl phosphorylcholine and lecithin was assayed in a mixture containing I mg of unlabeled lysolecithin commercially obtained from Sigma Company, St. Louis, Mo. (U.S.A.), $0.125 \mathrm{ml}$ of a $20 \%$ albumin solution freed of fatty acids by the method of Goodman ${ }^{15}, 0.05 \mathrm{ml}$ of $0.06 \mathrm{M}$ phosphate buffer $(\mathrm{pH} 6.0)$ and water to give a final volume of $0.4 \mathrm{ml}$.

When the breakdown of $\left.{ }^{32} \mathrm{P}\right]$ diacyl phosphoglycerides was examined, homogeneous dispersion of the labeled material in a solution containing $0.02 \mathrm{M} \mathrm{CaCl}_{2}$, 
phosphate buffer and water was achieved by ultrasonication. No carrier lecithin or phosphatidylethanolamine was added.

Prior to incubation $0.1 \mathrm{ml}$ of the leukocyte homogenate or one of its fractions was added. Enzymatic activity was interrupted by addition of $\mathrm{ro} \mathrm{ml}$ of a mixture of equal volumes of chloroform and methanol.

After standing overnight at $4^{\circ}$, the extracts were filtered, transferred quantitatively to an evaporator flask, and the solvents taken to dryness in a rotary evaporator. The remaining material was taken up in a few drops of methanol and streaked with a glass capillary upon silicated paper. Separation of the phospholipid fractions was achieved in the solvent mixture of MARINETTI ${ }^{13}$. When ${ }^{14} \mathrm{C}$-labeled fatty acids were present in the assay mixture, these or other non-phospholipid-lipid materials were separated from the phospholipids by prior chromatography in chloroform-light petroleum (b.p. 30-60 $)$-acetic acid $(65: 33: 2, v / v)$. Following separation and identification of the phospholipids, the desired fractions were cut out, cut into small pieces and placed into glass counting phials. Radioactivity of the fractions was determined in a Packard spectrometer after addition of $10 \mathrm{ml}$ of toluene containing $5 \mathrm{~g}$ of 2,5 diphenyloxazole and $0.3 \mathrm{~g}$ of $\mathrm{I}, 4$-bis-2-(5-phenyloxazolyl)-benzene per liter as scintillator.

Radioactivity of pieces of the strips taken from between the phospholipid spots, and corresponding in size to those cut to isolate the fractions, was subtracted as blank. This radioactivity did not exceed 2 times background radioactivity.

The product of hydrolysis of lysolecithin was identified as glyceryl phosphorylcholine by chromatography against the pure substance in propanol-ammonia-water ${ }^{\mathbf{1 6}}$ $(6: 3: 1, v / v)$.

For the preparation of lysolecithin labeled with $\mathrm{I}^{14} \mathrm{C}$-labeled long-chain fatty acid the following procedure was used: Advantage was taken of the pronounced ability of erythrocytes to acylate lysolecithin ${ }^{9,17-20}$. Since a marked specificity exists of saturated and unsaturated fatty acids for the $I$ and 2 ester position respectively, it was possible to prepare lysolecithin with $\left[\mathrm{I}^{14} \mathrm{C}\right]$ palmitic acid by exposing lecithin from erythrocytes incubated with this radioactive fatty acid to Crotalus adamanteus venom as previously described ${ }^{9}$. In this manner ${ }^{14} \mathrm{C}$-labeled lysolecithin was prepared with a radioactivity of approx. 75000 counts $/ \mathrm{min} / \mathrm{mg}$ of lysolecithin.

\section{RESUITS}

\section{Metabolism of $\left[{ }^{32} P\right]$ lysolecithin by homogenates of leukocytes}

Fig. I shows a distinctly acid $\mathrm{pH}$ optimum for the formation of lecithin whereas breakdown to glyceryl phosphorylcholine appcars maximal around ncutral $\mathrm{pH}$.

In the first ro min of incubation at $37^{\circ}$ at $\mathrm{pH} 5.0$, more than $75 \%$ of the $\left[{ }^{32} \mathrm{P}\right]$ lysolecithin present had been converted to either glyceryl phosphorylcholine or to lecithin (Fig. 2). Breakdown of lysolecithin to glyceryl phosphorylcholine exceeded by far the formation of lecithin. The latter reached a maximum within Io min while glyceryl phosphorylcholine accumulation seemed not yet to have come to a halt.

The possibility suggested itself that the rapid and more extensive hydrolysis to glyceryl phosphorylcholine, even at $\mathrm{pH} 5.0$, accounted for the limited formation of lecithin by removal of lysolecithin. An attempt was therefore made to inhibit the breakdown of lysolecithin to glyceryl phosphorylcholine, thus perhaps favoring 


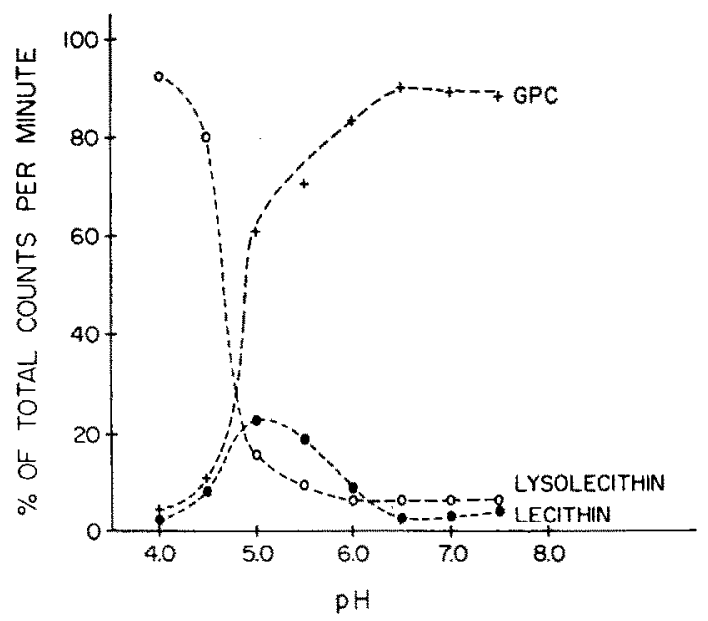

Fig. I. Effect of $\mathrm{pH}$ upon conversion of [ $\left.{ }^{32} \mathrm{P}\right]$ lysolecithin to glyceryl phosphorylcholine (GPC) and lecithin. Incubation was carried out for $3^{\circ} \mathrm{min}$ at $37^{\circ}$ as described in METHoDs, except for variation of $\mathrm{pH}$ by addition of $\mathrm{o}$. I $\mathrm{N} \mathrm{NaOH}$ or $\mathrm{H} \mathrm{Cl}$.

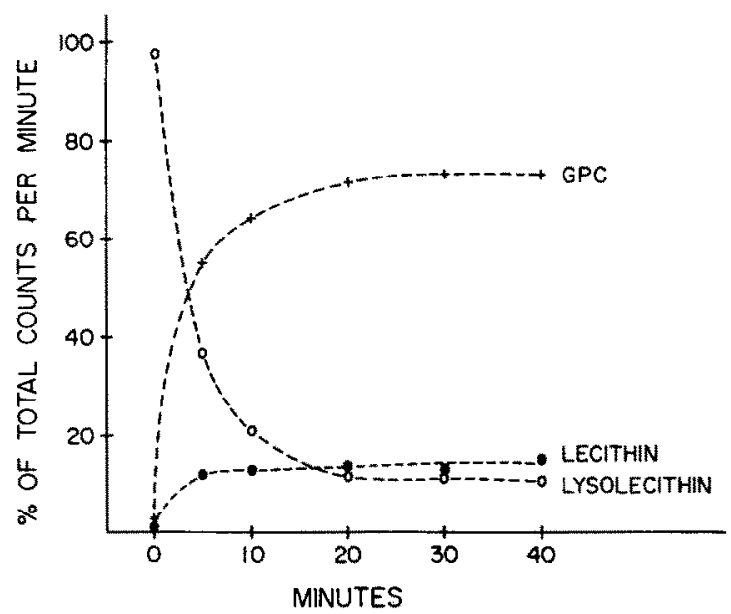

Fig. 2. Effect of time upon conversion of [32P]lysolecithin to glyceryl phosphorylcholine (GPC) and lecithin. Incubation was carried out at $37^{\circ}$ at $\mathrm{pH} 5.0$ as described in METHODS.

synthesis of lecithin. Deoxycholate is an effective inhibitor of lysophospholipase ${ }^{20}$. However, as shown in Table I, partial prevention of hydrolysis of lysolecithin did not stimulate lecithin formation but in fact resulted in inhibition.

\section{Phospholipase activity}

An alternative or additional explanation for the limited formation of lecithin could be the diacyl phosphoglyceride-splitting activity which is present in homogenates of leukocytes".

Fig 3 shows that this activity represents phospholipase A activity. Biosynthetically prepared [ ${ }^{2}$ P]phosphatidylcholine and phosphatidylethanolamine were 
isolated as described in the section on METHODS and dispersed in trace amounts in the assay mixture by ultrasonication. Fig. $3 \mathrm{~A}$ shows that upon incubation of leukocyte homogenates with $\left[{ }^{32} \mathrm{P}\right]$ lecithin a very small amount of lysolecithin accumulated at acid $\mathrm{pH}$, but the major portion of the radioactivity released from $\left[{ }^{32} \mathrm{P}\right]$ lecithin was

\section{TABLE I}

EFFECT OF ADDition OF DEOXYCHOLATE OR ATP, CoA AND $\mathrm{MgCl}_{2}$ UPON CONVERSION OF [2P ${ }^{32}$ LYSOLECITHIN TO GLYCERYL PHOSPHORYLCHOLINE AND LECITHIN

\begin{tabular}{|c|c|c|c|}
\hline & \multicolumn{3}{|c|}{ Per cent of total radioactivity in: } \\
\hline & Lysolecithin & $\begin{array}{l}\text { Glyceryl phos- } \\
\text { phorylcholine }\end{array}$ & Lecithin \\
\hline $\begin{array}{c}\text { No addition } \\
(8)\end{array}$ & $27.7 \doteq \mathbf{I} .3$ & $59.7=14.9$ & $12.7 \pm 5.7$ \\
\hline $\begin{array}{l}\text { Deoxycholate } \\
\text { (5) }\end{array}$ & $\begin{array}{l}71.9 \quad 1 . \mathrm{I} 6.0 \\
P<0.01\end{array}$ & $\begin{array}{l}23.4 \pm 14.2 \\
P<0.001\end{array}$ & $\begin{array}{l}4.7 \text { i. } 2.1 \\
P<0.02\end{array}$ \\
\hline$\underset{\text { (5) }}{\mathrm{ATP}, \mathrm{CoA}, \mathrm{MgCl}_{2}}$ & $\begin{array}{l}34.8 \pm 9.4 \\
P<\text { o.00 I }\end{array}$ & $\begin{array}{l}12.9+1.7 .6 \\
P<0.001\end{array}$ & $\begin{array}{l}2.3 \div 2.0 \\
P<\mathrm{OOI}\end{array}$ \\
\hline
\end{tabular}

Incubation was carried out for $30 \mathrm{~min}$ at $\mathrm{pH} 5.0$ as described in METHons. Additions: deoxycholate (sodium salt) $2 \mu$ moles; ATP (di-sodium salt) $5 \mu$ moles; CoA $0.1 \mu$ mole; $\mathrm{MgCl}_{2}$ to give final concentration of $5 \cdot 10^{-3} \mathrm{M}$.

The figure between parentheses indicates the number of observations.

The results are given as mean one standard deviation.

The $P$ values are given in reference to the controls (no addition) and were determined by Students' t-test.

$A$

NO AODITIN

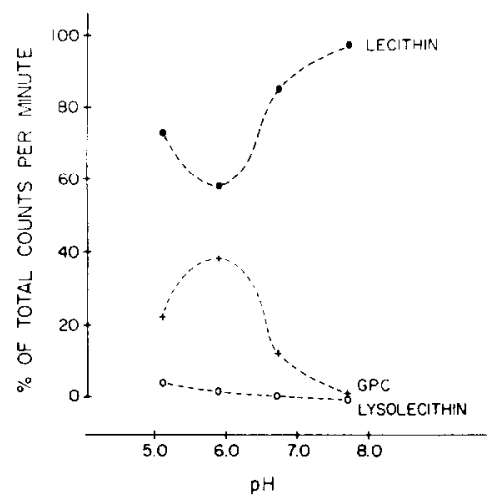

$\mathrm{B}$

+ Na DEOXYCHOLATE

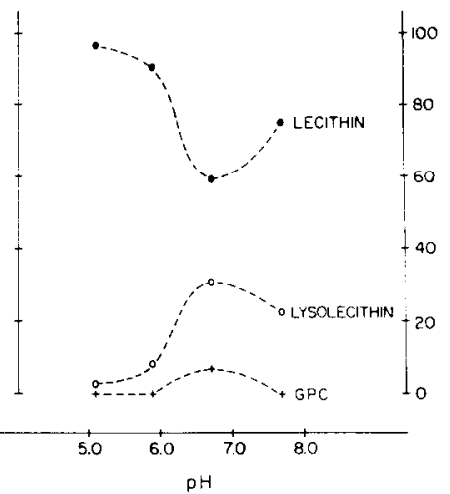

Fig. 3. Effect of $\mathrm{pH}$ and deoxycholate on conversion of $\left[{ }^{32} \mathrm{P}\right]$ lecithin to lysolecithin and glyceryl phosphorylcholine (GPC). Incubation was carried out at $37^{\circ}$ for $30 \mathrm{~min}$ as described in METHODS.

recovered in glyceryl phosphorylcholine. The abscissa shows the $\mathrm{pH}$ range studied, the ordinate the relative amounts of radioactivity in the compounds indicated.

Deoxycholate was added to the reaction mixture in a parallel experiment to inhibit lysophospholipase activity in order to establish that lysolecithin was indeed an intermediate in the breakdown of lecithin (Fig. $3 \mathrm{~B}$ ). The amount of lecithin broken down was comparable in the presence and absence of deoxycholate, but glyceryl phosphorylcholine formation was greatly inhibited, while lysolecithin accumulation 
was clearly demonstrable. Noteworthy is that greatest breakdown of lecithin in the presence of deoxycholate took place at a higher $\mathrm{pH}$ than in its absence. The $\mathrm{pH}$ of the assay mixture before and after incubation was not altered by addition of sodium deoxycholate.

A similar experiment (not shown) carried out with $\left[{ }^{32} \mathrm{P}\right]$ phosphatidylethanolamine demonstrated that this phosphoglyceride is broken down to approximately the same extent to its lyso-derivative.

Since these findings indicated the presence of phospholipase A activity in the leukocyte homogenates, the early plateau found for the formation of lecithin (Fig. 2) may be due in part to an equilibrium between the hydrolytic and synthetic activities in the homogenate.

\section{Comparison of conversion of $\left[{ }^{32} P\right] l y$ solecithin by homogenates of resting and phagocytizing leukocytes}

During phagocytosis lipid synthesis by polymorphonuclear leukocytes is enhanced as judged by incorporation of $\left[\mathrm{I}^{-14} \mathrm{C}\right]$ acetate and ${ }^{32} \mathrm{P}$ into both phospholipids and non-phospholipids ${ }^{1,2}$. It has been postulated that increased phospholipid metabolism during phagocytosis may reflect increased turnover of both external and internal membranous structures ${ }^{2}$. In a few experiments a comparison was made between the conversion of lysolecithin into both glyceryl phosphorylcholine and lecithin by homogenates of resting and actively engulfing leukocytes. In addition, various fractions of these homogenates were examined for their activities.

\section{TABLE II}

EFFECT OF PHAGOCYTOSIS OF HEAT-KILLED STREPTOCOCCI CPON CONVERSION OF [32P'LYSOLECITHIN TO GLYCERYL PHOSPHORYLCHOLINE AND LECITHIN

The cell suspension, freshly drained from the peritoneal cavity of one or more rabbits, was divided into two equal portions, which were centrifuged for Io min at low speed. After decantation of the ascitic fluid, the cells were resuspended in $5 \mathrm{ml}$ of the same fluid and incubated with or without heat-killed streptococci in physiologic saline in an approximate ratio of 10 bacteria to $\mathbf{I}$ leukocyte ${ }^{1}$. Following incubation at $37^{\circ}$ for $20 \mathrm{~min}$, the leukocytes were separated from the ascitic fluid by centrifugation. Homogenization of the packed cells and the subsequent assay were carried out as described in the section on METHODs.

All results have been expressed as per cent of the control value in the whole homogenate in each of 3 experiments. The $8200 \times g$ sediment (granule fraction ${ }^{11}$ ) contained barely detectable activity.

\begin{tabular}{|c|c|c|c|}
\hline & & $\begin{array}{l}\text { Glyceryl phos- } \\
\text { phorylcholine }\end{array}$ & Lecithin \\
\hline \multirow[t]{2}{*}{ Whole homogenate: } & Control & 100 & IOO \\
\hline & Strep.* & $\begin{array}{l}\text { I30 } \\
80 \\
88.5\end{array}$ & $\begin{array}{r}195 \\
95 \\
67\end{array}$ \\
\hline \multirow[t]{2}{*}{$\begin{array}{l}\text { Supernatant fraction: } \\
\quad(8200 \times g)\end{array}$} & Control & $\begin{array}{l}45 \\
8 I\end{array}$ & $\begin{array}{r}49 \\
205\end{array}$ \\
\hline & Strep.* & $\begin{array}{c}5 \\
23 \cdot 5 \\
5 \mathbf{I} \cdot 5\end{array}$ & $\begin{array}{c}5^{8} \\
5 \mathrm{I} \cdot 5 \\
200\end{array}$ \\
\hline \multirow[t]{3}{*}{$\begin{array}{l}\text { Sediment: } \\
\qquad(400 \times g)\end{array}$} & Control & $\begin{array}{l}32 \\
37 \\
25\end{array}$ & $\begin{array}{l}35 \\
34 \\
27\end{array}$ \\
\hline & Strep.* & 42.5 & 29 \\
\hline & & 44 & 37 \\
\hline
\end{tabular}

* Strep., heat-killed streptococci added to intact leukocytes prior to incubation. 
Table II shows that whole homogenates of cells that had ingested heat-killed streptococci manifested no greatly different activity. The distribution of the activity among the $8200 \times g$ supernatant fraction and the sediment obtained by centrifugation of the whole homogenate at $400 \times g$ was also roughly comparable in resting and engulfing cells. The granule fraction contained little activity.

\section{Studies concerning the mechanism of lecithin formation from $\left[{ }^{32} P\right] l y$ solecithin}

Two findings rendered it less likely that the direct acylation of lysolecithin as described by LANDS et al. ${ }^{\mathbf{2 1 - 2 4}}$ accounted for the observed formation of lecithin by polymorphonuclear leukocytes. (a) In contrast to observations on other tissues where this reaction is active ${ }^{19-21}$, supplementation of the reaction mixture with ATP, CoA and $\mathrm{MgCl}_{2}$ not only did not enhance lecithin formation but suppressed it (Table I)* (Omission of $\mathrm{MgCl}_{2}$ did not alter the inhibitory effect of ATP and CoA). (b) The addition of trace amounts of $\left[\mathrm{I}^{-14} \mathrm{C}\right]$ linoleic acid with high specific activity resulted in barely detectable appearance of ${ }^{14} \mathrm{C}$-radioactivity in the lecithin fraction while conversion of $\left[{ }^{32} \mathrm{P}\right] l y s o l e c i t h i n$ to lecithin clearly took place.

An alternative mechanism for the synthesis of lecithin from lysolecithin has been postulated by ERBLAND AND MARINETTI?. This hypothesis proposes that 2 lysolecithin $\rightarrow$ lecithin and glyceryl phosphorylcholine. Such a mechanism was rendered probable by studies in yeast ${ }^{8}$ and has now been proven to exist in erythrocytes by Mulder et al. ${ }^{9}$ and in liver and lung by VAN DEN Bosch**. The method of demonstration of the relative importance of the direct acylation reaction and the acyltransferase reaction rests upon the determination of the isotope ratio of lecithin formed from lysolecithin labeled with ${ }^{32} \mathrm{P}$ in the phosphorylcholine moiety and with ${ }^{14} \mathrm{C}$ in the carboxyl group of the fatty acid in the I-position. In the presence of excess unlabeled lysolecithin and free fatty acid relative to the labeled material it may for example be concluded if the ratio ${ }^{14} \mathrm{C} /{ }^{32} \mathrm{P}$ in the lecithin formed remains cqual to that in the lysolecithin, that no ${ }^{14} \mathrm{C}$-labeled fatty acid was transferred and that direct acylation must have occurred. Conversely a doubling of the ratio ${ }^{14} \mathrm{C} /{ }^{32} \mathrm{P}$ would signify that the lecithin molecules formed gained a ${ }^{14} \mathrm{C}$-labeled fatty acid while the ${ }^{32} \mathrm{P}$ remained constant, implying the transfer of ${ }^{14} \mathrm{C}$-labeled fatty acid from lysolecithin. The addition of ATP and CoA should lower the ratio if direct acylation were stimulated.

As indicated in Table III, incubation of homogenates with lysolecithin carrying 2 labels resulted in formation of lecithin with an isotope ratio approximately $2 \times$ that of lysolesithin. Addition of ATP and CoA, which, as already shown in Table I can inhibit lecithin accumulation, in this system did not bring about significant alteration in the isotope ratio. This is in contrast to findings with homogenates of other cells which are capable of direct acylation of lysolecithin ${ }^{9}$.

\section{DISCUSSION}

These results have confirmed previous observations on the presence of phospholipid-splitting activities in leukocyte homogenates ${ }^{6}$. Both phospholipase A (phosphatide acyl-hydrolase, EC 3.I.I.4) and lysolecithinase (EC 3.I.I.5) activities have

* Even more striking is the decreased production of glyceryl phosphorylcholine in the presence of ATP and CuA. This unexpected ubservation is under further investigation.

** Unpublished observations. 
TABLE III

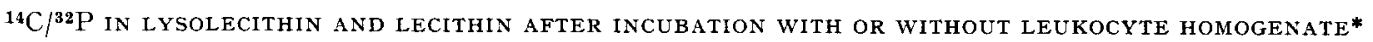
Incubation was carried out for $30 \mathrm{~min}$ at $\mathrm{pH} 5.0$, as described in METHoDs. All reaction mixtures contained $2 \mu$ moles of unlabeled lysolecithin, $0.2 \mu$ mole of $\left.{ }^{14} \mathrm{C}\right]$ lysolecithin, trace amounts of [ $\left.{ }^{32} \mathrm{P}\right]$ lysolecithin; I $\mu \mathrm{mole}$ of linoleic acid complexed to defatted albumin; $\mathrm{MgCl}_{2}$ in a final concentration of $5.10^{-3} \mathrm{M} \mathrm{ATP}$ and CoA were added in amounts of 5 and $0.1 \mu$ moles respectively.

\begin{tabular}{|c|c|c|c|c|c|c|c|c|c|}
\hline & \multicolumn{3}{|c|}{ Lysolecithin $(A)$} & \multicolumn{3}{|c|}{ Lecithin (B) } & \multicolumn{3}{|l|}{$B / A$} \\
\hline & Expt.I & Expt. 2 & Expt. 3 & Expt.I & Expt.2 & Expt. 3 & Expt.I & Expt. 2 & Expt. 3 \\
\hline No homogenate added & 0.85 & I. 2 & $0.7^{\circ}$ & $\longrightarrow$ & - & - & - & 一 & - \\
\hline $\begin{array}{l}\text { + whole homogenate } \\
+ \text { whole homogenate and }\end{array}$ & $0.8 \mathrm{I}$ & I. 2 & 0.74 & I. 65 & 2.35 & 1.78 & 2.0 & 1.9 & 2.4 \\
\hline ATP, COA & 0.72 & $\mathrm{I} \cdot 3$ & $0.7 \mathrm{I}$ & $*$ & $2.9^{*}$ & $1.42^{*}$ & - & 2.2 & 2.0 \\
\hline
\end{tabular}

* In the presence of ATP and CoA insufficient isotope incorporation into lecithin took place in Expt. $\mathbf{I}$; in Expt. 2, the determination of the isotope ratio is only approximate; in Expt. 3 sufficient lecithin was formed to allow a reliable determination.

been identified. The former activity exhibited a distinctly acid $\mathrm{pH}$ optimum whereas the latter activity was most pronounced at neutral or higher $\mathrm{pH}$. These observations using conversion of ${ }^{32} \mathrm{P}$-labeled glycerol phosphatides for detection of enzymatic activity are in accord with the earlier results obtained by determination of release of fatty acids from unlabeled substrates ${ }^{6}$.

We have no ready explanation for the shift in $\mathrm{pH}$ optimum noted when $\mathrm{Na}$ deoxycholate was added to the reaction mixture containing $\left.{ }^{[32} \mathrm{P}\right]$ lecithin. However, inhibition of further breakdown of lysolecithin to glyceryl phosphorylcholine clearly demonstrated lysolecithin accumulation and therefore the presence of phospholipase A activity in the homogenate.

In addition, it has been shown that $\left[{ }^{32} \mathrm{P}\right]$ lysolecithin is converted directly into lecithin. The probable mechanism of this reaction is a transfer reaction in which 2 lysolecithin molecules participate to form lecithin and glyceryl phosphorylcholine.

The most convincing evidence for the existence of this reaction derives from the use of ${ }^{14} \mathrm{C}$ - and ${ }^{32} \mathrm{P}$-labeled lysolecithin as precursors of lecithin. The doubling of the isotope ratio indicates that one of the two lysolecithin molecules contributed its fatty acid to the formation of lecithin. This conclusion is further supported by the following observation: in contrast to the stimulatory effect of added ATP and CoA on the acylation of lysolecithin according to the mechanism described by LANDS (refs, 2r-24), in this study addition of acylation-promoting substances not only did not enhance lecithin formation, but suppressed this reaction. Furthermore, while lecithin accumulation could be clearly demonstrated, the leukocyte homogenate did not incorporate significant quantities of ${ }^{14} \mathrm{C}$-labeled free fatty acid into lecithin. The free fatty acid content of leukocytes constitutes only a few per cent of the total fat content ${ }^{1}$. Addition of carboxyl-labeled linoleic acid of high specific activity therefore should allow the detection of acylation of even small amounts of free fatty acid, relative to the quantity of lysolecithin converted to lecithin (more than $200 \mathrm{~m} \mu$ moles/o.I ml of homogenate, representing approx. I0 $^{7}$ cells).

To what extent the rapid breakdown of [ $\left.{ }^{32} \mathrm{P}\right]$ lysolecithin to glyceryl phosphorylcholine interfered with synthesis of lecithin has not been definitely determined. Inhibition of glyceryl phosphorylcholine formation by adding deoxycholate to the reaction mixture inhibited production of $\left.{ }^{32} \mathrm{P}\right]$ lecithin as well. The inhibitory effect of deoxycholate and also of ATP and CoA not only on the conversion of lysolecithin to lecithin 
but also on the formation of glyceryl phosphorylcholine might be explained, if the reaction 2 lysolecithin $\rightarrow$ lecithin and glyceryl phosphorylcholine accounted entirely for the glyceryl phosphorylcholine formed. The coexistence of the acyl transferase and the phospholipase A activity would explain the limited amount of $\left[{ }^{32} \mathrm{P}\right]$ lecithin formed, breakdown and synthesis apparently taking place at equal rates. This would also explain the greater formation of glyceryl phosphorylcholine, since with each lecithin molecule formed a lysolecithin molecule is removed as glyceryl phosphorylcholine. The turnover of $\left[{ }^{32} \mathrm{P}\right]$ lecithin would thus determine the rate of $\left[{ }^{32} \mathrm{P}\right]$ glyceryl phosphorylcholine accumulation and consequently no separate lysophospholipase in the strict sense need be present. However, the reaction lysolecithin $\rightarrow$ glyceryl phosphorylcholine clearly occurs maximally at $\mathrm{pH} 7.0$ and higher, while both phospholipase A activity and reformation of lecithin exhibit acid $\mathrm{pH}$ optima. Furthermore, at the concentrations of substrate used ( $4 \mathrm{mM}$ ), breakdown of lysolecithin to glyceryl phosphorylcholine exceeded $60 \%$ of the lysolecithin initially present, while phospholipase $\mathrm{A}$ activity at a similar substrate concentration results in hydrolysis of no more than a few per cent of the lecithin in the reaction mixture ${ }^{6}$, rendering it unlikely that the turnover of lecithin is fast enough to account for the rapid appearance of glyceryl phosphorylcholine.

We believe therefore that the data presented are consistent with the conclusion that the following three enzymatic reactions take place in the leukocyte:

Lecithin $\rightarrow$ Lysolecithin

Lysolecithin $\rightarrow$ Glyceryl phosphorylcholine

2 lysolecithin $\rightarrow$ Lecithin and glyceryl phosphorylcholine

It further appears that under the conditions of these experiments direct acylation of lysolecithin does not take place to an appreciable extent.

Morphologic evidence strongly suggests a markedly increased formation and breakdown of outer and intracellular membrane during phagocytosis ${ }^{25}$. Compounds such as lysolecithin might play a dual role in this enhanced turnover of membrane; (a) as membrane-lytic agents ${ }^{27}$, and (b) as precursors of lecithin or other phosphoglycerides in the reconstruction of membrane as is seen in the pinching off of outer membrane and in the apparent fusion of phagocytic vacuoles with the lysosomes of the granulocyte ${ }^{26}$.

It is of particular interest that the observed conversion of lysolecithin to lecithin does not require addition of ATP and CoA. Moreover, lysolecithin produced locally when favorable conditions for pliusploulipase A activity prevail can be utilized for the regeneration of lecithin. It appears therefore that with little expenditure of biochemical energy for synthesis the leukocyte can manufacture important membrane constituents.

Previously one of us has postulated that the difference in $\mathrm{pH}$ optimum for phospholipase $\mathrm{A}$ and lysolecithinase activity may regulate the amount of the membrane-lytic agent lysolecithin in resting and phagocytic leukocytes ${ }^{6}$. If the determination of $\mathrm{pH}$ optima in vitro has a bearing upon maximal activity in the intact cell, the drop in intracellular $\mathrm{pH}$ which accompanics phagocytosis ${ }^{28}$ would give rise to a simultaneous reduction in lysolecithinase and activation of phospholipase A activities, causing increased formation of lysolecithin.

While increased radioisotope incorporation into phospholipids in actively engulfing leukocytes has been demonstrated, net synthesis has not been shown to 
occur ${ }^{1,2}$. Furthermore ${ }^{32} \mathrm{P}$ incorporation is only significantly greater into phosphatidic acid, phosphatidyl serine and phosphatidyl inositol ${ }^{29}$. These compounds comprise a small percentage of the phospholipids of the leukocyte, and the relevance to membrane formation of the increased incorporation of ${ }^{32} \mathrm{P}$ into these substances remains to be determined.

However, neither a failure to detect net synthesis of phospholipid by intact leukocytes during phagocytosis nor our inability to demonstrate that homogenates of actively phagocylizing leukocyles converted more lysolecithin into lecithin need imply that in the microanatomy of the granulocyte conditions may not prevail locally allowing increased membrane synthesis. The quantitative significance of such local processes relative to total phospholipid metabolism might not be sufficient to allow their demonstration in whole cells or homogenates, nor necessarily in the fractions examined.

\section{ACKNOWLEDGEMENTS}

P. E. is a Career Scientist of the Health Research Council of the City of New York. Work carried out as guest investigator in the laboratory of Professor L. L. M. VAN DeEnen. This work was supported in part by grants from the United States Public Health Service (AM I5472 and GM rorg8).

\section{REFERENCES}

I P. Elsbach, $J$. Exptl. Med., i io (1959) 969.

2 A. J. Sbarra and M. L. Karnovsky, J. Biol. Chem., 235 (1960) 2224.

3 P. Elsbach, Biochim. Biophys. Acta, 7o (1963) I 57.

4 W. H. Evans and P. S. Mueller, J. Lipid Res., 4 (I963) 39.

5 P. Elsbach, Biochim. Biophys. Acta, 84 (1964) 8.

6 P. Elsbach and M. A. Rizack, Am. J. Physiol., 205 (1963) II 54.

7 J. F. Erbland and G. V. Marinetti, Federation Proc., 2 I (I962) 295.

8 R. Kokke, G. J. M. Hooghwinkel, H. L. Booij, H. Van Den Bosch, L. Zelies, E. Mulder AN. L. L. M. VAN DeEnen, Biochim. Biophys. Acta, 7o (1963) 351

9 E. Mulder, J. W. O. Van Den Berg and L. L. M. Van Deenen, Biochim. Biophys. Acta, in the press.

io P. Elsbach and 1. L. Schwartz, J. Gen. Physiol., 42 (1959) 883.

I I Z. A. Cohn and J. G. Hirsch, $J$. Exptl. Med., I I 2 (I960) 983.

i 2 E. S. Bligh and W. J. Dyer, Can. J. Biochem. Physiol., 37 (1959) 91 1.

I 3 G. V. Marinetti, J. Lipid Res., 3 (1962) I.

I 4 G. H. De Haas, F. J. M. Daemen and L. L. M. Van Deenen, Biochim. Biophys. Acta, 65 (I962) 260.

I5 D. S. Goodman, Science, I25 (1957) 1297.

I6 J. Olley and R. M. C. Dawson, Biochem. $J$., 62 (1956) 5 P.

I7 M. M. Oliveira and M. Vaughan, Fedevation Proc., 2 I (I962) 296.

i 8 L. L. M. Van Deenen, J. De Gier, U. M. T. Houtsmuller, A. Montfoort and E. Mulder, in A. C. Frazer, Biochemical Problems of Lipids, Elsevier, Amsterdam, 1963, p. 404.

I9 M. M. Oliveira and M. Vaughan, J. Lipid Res., 5 (1964) I 56.

20 A. F. Robertson and W. E. M. Lands, J. Lipid Res., 5 (1964) 88.

2 I W. E. M. LANDS, J. Biol. Chem., 235 (I960) 2233.

22 W. E. M. Lands and I. MerkL, J. Biol. Chem., 238 (I963) 898.

23 I. Merki and W. E. M. Lands, J. Biol. Chem., 238 (I963) 905.

24 W. E. M. Lands and P. HaRT, J. Lipid Res., 5 (1964) 81 .

25 J. G. Hirsch, J. Exptl. Med., II6 (I962) 827.

26 D. Zucker-Franklin and J. G. Hirsch, J. Exptl. Med., i 20 (1964) 569.

27 G. Weismann, B. Becher and L. Thomas, J. Cell Biol., 22 (I964) 1 I 5.

28 P. Rous, J. Exptl. Med., 4I (1925) 399.

29 M. L. Karnovsky and D. F. Hoelzl Wallach, J. Biol. Chem., 236 (I96I) I895. 